\title{
NOTA \\ DEL PRINCIPIO INFORMADOR DEL CODIGO DEL MEDIO AMBIENTE Y LOS RECURSOS NATURALES
}

M. Donayre P.*

El desarrollo de nuestras economías ha traído como consecuencias graves daños al entorno en el cual vivirnos; como ejemplo de ello tenemos la contaminación de las aguas del río Rfmac a niveles intolerables o la depredación en nuestra A mazonía ante la práctica de migrantes andinos de agricultura intensiva y sedentaria. $Y$, es así dentro de este contexto de desarrollo y conservación del ambiente que se gesta el Código del Medio A mbiente y los Recursos Naturales.

\section{Antecedentes de la R esponsabilidad Extracontractual. Doctrina}

Nuestra legislación civil optó en materia de responsabilidad para determinar los daños por la teoría subjetiva de la culpa ${ }^{1}$ Esta teoría de la culpa $^{1}$ o subjetiva, mal llamada aquiliarta ${ }^{2}$ parte del entendimiento que ante una conducta negligente que causa un daño, menoscabo a la persona (s) 0 cosas debe ser comparada, haciendo una abstracción, con la conducta de un buen padre de familia o responder al arquetipo de un hombre responsable y allí encontrar la responsabilidad. Ir a la causa, buscar al culpable y castigarlo moral y pecuniariamente.

Esta teoría de la culpa en nuestra tradición civilista, sufre las primeras fisuras en las sesiones de debate en la Comisión Reformadora del Código Civil de $1852{ }^{3}$ A quel célebre debate entre $M$ anuel Augusto Olaechea y Juan José Calle, el

León Barandiarán, Josa. Curso del acto jurídico, con referencia al Proyecto del Código Civil Peruano. Lima 1983; Rey de Castro, J orge. Editorial de la Universidad M ayor de San M arcos, Lima, 1972. Vidal Ramfrez, Fernando " $L$ a responsabilidad extracontractual en el código civil de 1984. Revista Derecho, PUC, Lima 1989; León Barandiarán, José, Responsabilidad Extracontractual. Exposición de motivos y Comentarios, en Delia Revoredo de Debakey (cd); Código Civil. Vol. VI. Comisión Encargada del Estudio y la Revisión del Código Civil de 1936. Lima, 1985; De Trazegnies, Fernando "Para una lectura creativa de la responsabilidad extracontractual" Colección para leer el Código Civil, Fondo Editorial PUC, Lima $10 \mathrm{~cd}$. 1985.2 Véase el sugerente estudio de Sandro Schipani, Responsabilita "ex lege Aquilia". Criteri di imputazione e problema della "culpa'. Universitá de Tormo. G. Giappichelli, Editora. Tormo, 1969 y de Fernando De Trazegnies en "La responsabilidad extracontractual" en Para Leer el Código Civil, Lima, $10 \mathrm{~cd}$. 1988.

3 n excelente compendio de debate lo encontramos en la obra de Fernando De Trazegnies. "La responsabilidad extracontractual" ob .cit.

stituto de Investigaciones de la A mazonía Peruana-IIA P. Av. A belardo Quiñones m. 2.5 A panado 784. IquitosPerú. 
primero sustentaba la teoría objetiva de la responsabilidad, y el segundo abogaba por la teoría de la culpa.

Donde encontramos que los criterios del factor de atribución de la culpa sufre el mayor embate es en la Comisión R eformadora del Código Civil de 1936, con el Anteproyecto propuesto por Femando De Trazegnies "De la responsabilidad no derivada del acto jurídico" ${ }^{4}$

El mencionado A nteproyecto postula por una nueva forma de asignar los daños en la sociedad moderna, a través de la teoría de la distribución social de los daños. $Y$, dentro de esta perspectiva y consciente del proceso de canibalización y cercenamiento que atraviesa el derecho $\mathrm{civil}^{5}$ se propone incorporar los daños al medio ambiente y del consumidor, así como un tratamiento especial de la responsabilidad de los profesionales ${ }^{6}$

L a teoría de difusión social de los daños tiene su génesis en la teoría del riesgo en su connotación objetiva. Es decir, es una teoría repensada del riesgo, porque inicialmente se asignaba el daño a quién creaba riesgo, y las críticas sobre esta teoría se basaban en que era un mecánico traslado del culpable como lo hacía la teoría subjetiva, el axioma objetivista era: quien crea un riesgo debe asumirlo e indemnizar si se sufría daños.

La teoría objetiva encontró ciertos obstáculos en relación a los argumentos moralistas que esgrimían los críticos suhjetivistas ${ }^{7}$, y de estas críticas de los daños ${ }^{8}$ parte es teoría de la difusión social de las cosas, donde se establecen que las sociedades contemporáneas necesitan para cumplir sus objetivos sociales de ciertas situaciones que producen riesgo y se benefician de ellos toda la sociedad. Es decir, la sociedad tiene también participación en la creación del riesgo, y ésta debe asimilar el peligro a través de diferentes mecanismos que proporciona la

Comisión encargada del Estudio y Revisión del Código Civil de 1936: Proyectos y A nteproyectos de la reforma del Código Civil. Fondo Editorial de la Pontificia Universidad Católica. Lima, 1980.

5 Esta propuesta de canibalización y cercenamiento ha sido advertido por Fernando De Trazegnies en La responsabilidad extracontractual" T. 11. Pág. 418 y sostiene que la falta de adaptabilidad del Derecho Civil ha hecho perder terreno en los momentos actuales. A sí por ejemplo, en la actualidad hay un proyecto de ley en el Congreso de la República sobre la creación del Código de Familia, e inclusie de un M inisterio.

6 El anteproyecto era un instrumento jurídico de moderna asignación de responsabilidad a través de la difusión social de los daños, colisionó con los intereses de la sociedad de modernización tradicionalista.

7 Mazdaud, Henri y León; Ttinc, André: Tratado teórico y práctico de la responsabilidad civil delictual y contractual". En un discurso en memoria a Henri Capital manifiesta L eón M azeaud:

e advierte sai la amplitud del problema. Borrar de la responsabilidad la culpa, es al mismo tiempo, borrar del derecho civil la persona, para aplastarla bajo materia y bajo la sociedad". Advierten asi mismo los autores en la introducción, que estamos ante el hecho de la "cascada de las responsabilidad y, que los seguros ayudaría a generar más imprudentes".

Ver la obra de Guido Calabresi: “El costo de los accidentes “Editorial A riel, Barcelona 1984; De Trazegnies, Fernando. "La responsabilidad extracontractual" (obra ya citada); Payet, José A ntonio. "La responsabilidad por productos defectuosos" en Biblioteca Para Leer el Código Civil T.II., PUC. Lima 1990; donde se recogen los principios de la escuela $L$ aw \& Economics; M ercado Neuman, Edgardo. "Fundamentos del sistema de responsalidad civil extracontractual" en Themis, Segunda Epoca/1988/No 10 . 
economía de mercado, el sistema de precios y el sistema de seguros (en ambos casos, lo que se trata es de intemalizar el riesgo a través del precio y así difundirlo a la sociedad, si el producto resulta de costo muy elevado, entonces, no es conveniente para el usufructo de la sociedad).

La sociedad sería la difusora de los daños a través de los mecanismos de mercados citados, pero, no se filtran por ella todos los daños, porque hay daños que son intolerables. Un daño socialmente tolerable sería la velocidad de los automóviles, estas velocidades generan accidentes, pero la sociedad los tolera, los asume porque necesita de la velocidad para el transporte, las comunicaciones, el comercio entre otras actividades. Pero, hay otros daños que la sociedad no los tolera, por ejemplo tenemos la contaminación del aire a niveles no permitidos 0 el vertimiento de líquidos tóxicos (se supone, altamente tóxicos) en las aguas. $L a$ sociedad no permite estos daños porque afectan a todos y no es convenitne para ella misma por su sobrevivencia, porque conviene preservar el ambiente y mantenerlo ecológicamente equilibrado.

Entonces tenemos que, el documento propuesto por Femando De Trazegnies ha generado una ruptura con la tradicional manera de asignar los daños en nuestra tradición civilista.

Pero, a pesar de este avance sustantivo en nuestra doctrina civilista, de enfocar a la responsabilidad y de adecuarlo a la modernidad, el legislador dio marcha atrás y desdeñé esta propuesta ${ }^{9}$, pensó que mejor solucionaba estos problemas económicos es la teoría subjetiva o de la culpa. La duda dominé al legislador. Y, el resultado es el actual Código Civil de 1984.

El Legislador ante la propuesta de la difusión de los daños decidió por el bricoleaur conceptual de asimilar el principio informador de la culpa (A rt. 1969), y el factor de atribución objetivo (art. 1970 del Código Civil), aunque todavía pensando subjetivamente, pero esta dicotomía sería materia de otro trabajo.

\section{EL CODIGO DEL MEDIO AMBIENTE Y LOS RECURSOS NATURALES}

Dentro de estos precedentes de la doctrina y legislación expuestas, tenemos la promulgación y publicación del Código del M edio A mbiente y los Recursos Natuales, del 8 de setiembre de 1990, Decreto L egislativo № 163.

\footnotetext{
${ }^{9}$ La opción desarrollada por el legislador civil, contradice la tendencia de la doctrina contemporánea que avanza hacia una difusión social de los daños en diferentes perspectivas, ver Educardo Zannoni "El daño en la responsabilidad Civil" Editorial Astrea, Buenos Aires 1987; TRIGO REPRESAS, Félix y STIGLITZ, Rubén en "Derecho de Daños"; Alterini, Atilio "Contornos actuales de la responsabilidad" ediciones Perrot, Buenos Aires, 1980. El autor con precisión señala las tendencia de la responsabilidad moderna e incluso comenta de la escuela norteamericana Law \& Economies. El regresar hacia la teoría la culpa no permite contemplar los problemas actuales de la modernización de las sociedades, exempli gratis, tenemos los daños hacia el medio ambiente y el consumidor. Dada la naturaleza de estos daños; inminente, continuada y/o colectiva.
} 


\section{Breve referencia}

El Codigo del Medio Ambiente y los Recursos $N$ aturales ha sido discutido por la Comisión que redactó el Anteproyecto de Ley de Código del M edio A mbiente y los Recursos $N$ aturales, que contemplaba en relación a la responsabilidad, disposiciones que asimilaban el factor de atribución objetivo y de la difusión social de los daños e internalizaba la característica del daño ambiental, su naturaleza difusa; en cuanto a la defensa del ambiente, se podría decir que había el esfuerzo de introducir los conceptos de la acción de clase 0 de la "clase action".

A demás se tenía como referencia que la Constitución Política de 1979, en el artículo 123, trata de los intereses difusos relacionados con la defensa del medio ambiente, había una mejor conceptualización y se despojaba de ciertos criterios tradicionalistas que están en el actual CMA y RN ${ }^{11}$ y que todavía no son integrados por la legislación procesal ${ }^{12}$, M uchas veces la visión unidimensional del legislador dosifica los hechos y se produce lo que Viney llama "El contraste entre la relativa estabilidad de los textos legales y la amplitud de los cambios' ${ }^{13}$

\section{El Código del Medio Ambiente y Recursos Nnaturales}

EI vigente CMA y $R N$, ha asimilado el factor de atribución de la difusión social del riesgo (las internalidades) de la responsabilidad, por otro lado, deja al bricoleaur conceptual a la defensa del medio ambiente, en el sentido que, incorpora el moderno concepto de la difusión social del daño, pero procesalmente son tratados tradicionalmente. Sostenemos aquella premisa en razón que los costos de las acciones de control de la contaminación ambiental deben ser intemalizadas por quien genera el riesgo o peligro de la comintanción (artículo 1, inciso 6 del CMA y RN), e inclusive, control que consiste en la prevención, vigilancia recuperación y deterioro ambiental. El legislador nos dice que ciertas actividades tienen un "Costo Ambiental" que pueden causar deterioro 0 degradación al medio ambiente, y sin embargo los tolera (nos menciona en el artículo en referencia de la recuperación y deterioro ambiental). Es decir, estamos tratando los daños socialmente tolerables que incorpora el principio del

\footnotetext{
11 Ver anteproyecto de la Oficina Nacional de Evaluación de Recursos Naturales (ONERN); se tiene Conocimiento de otro anteproyecto de Código realizado por el CONAPMAS. EI primer anteproyecto contemplaba acciones de protección ambiental de manera colectiva y hacia una clasificación de los daños la manera de asignar los daños y el modo como la ciudadanía pudiera protestar de manera conjunta. $Y$, dentro de la naturaleza especial de estos daños, segón la doctrina, estas pueden ser: continuas y ocacionales.

12 La detieiencia procesal la anotamos en el anteproyecto del Código de Procedimientos Civiles donde no se hace mención alguna a las acciones colectivas de defensa del medio ambiente y de los consumidores. El derecho peruano, no se ajusta a la situación contemporánea industrial.

13 Citado en el prólogo de Derecho de daños” dirigida por Felix TRIGO REPRESAS y Rubén STIGLITZ, Ediciones La Rocca, Bs. As. 1989.
} 
derecho ambiental contaminador/pagador (quien contamina debe pagar) ${ }^{14}$ y al introducir estos costos en el producto final estamos desarrollando el concepto de las internalidades (que son correctores de precios en el mercado). $Y$, todos estos conceptos comentados (daños socialntente tolerables, principio contaminador/pagador) se integran dentro de la política ambiental propuesta por el CMA y RN. Entonces tenemos que estamos ante un tratamiento moderno de los daños, ya mediante la internalización de los costos ambientales, tratamos de difundir los daños a toda la sociedad ${ }^{15}$

Donde notamos una deficiencia conceptual en el CMA y RN, es en el tratamiento de los daños. No se ha esbozado una definición de los daños socialmente tolerables e intolerables (aunque sea de caracácter operativo), Ilegamos a ellos por interpretación. El legislador olvidó una de las características principales del Derecho A mbiental, su carácter disuasivo deterrence ${ }^{16}$ ante daños ambientales tenemos la vía penal, administrativa, civil, o en su caso, se presente las acciones constitucionales pertinentes.

Los daños ambientales son de naturaleza difusa y su tratamiento en el derecho merece la especialidad y modernidad, exernpli gratia, la defensa procesal a través de las acciones de clase. Ante daños ambientales eventuales; ¿cómo actuamos? o ante daños ambientales permanentes, ¿cuál sería nuestro proceder? Estas consideraciones han sido obviadas por el legislador.

EI CM A y RN, traslada el tratamiento de los daños hacia el derecho civil y como bien hemos visto, en el derecho civil se optó por el camino de la mixtura y se tratan los daños de un modo tradicional ${ }^{17}$. Es decir se eligió el moderno concepto de los daños, pero se buscó la vía tradicional para resolverlo (A rtículos 137, 138 y 141 del CM A y RN).

Finalmente, el CMA y RN recoge el moderno concepto de la difusión social de los daños a través de las internalidades. Pero, este paso hacia adelante retrocede dos, al dejar que estos daños sean tratados todavía desde la perspectiva tradicional:

Recursos administrativos, de la denuncia penal, acciones civiles o acciones constitucionales de amparo 0 en su caso, la acción popular o la acción de constitucionalidad.

\footnotetext{
14 Algunos autores critican este principio porque se puede pagar, y seguirse haciendo daños al medio ambiente, y no se cumpliría asi el principio disuasivo preventivo del derecho ambiental. Artículo 3 dcl Código del Medio Ambiente y Recursos Naturales. Este principio debe estar referido a los daños tolerables.

15 L as internalidades son aquellos "costos ambientales, asumidos por el productor al elaborar el precio final de un producto o bien. Otro caso de las internalidades" es el del art. 10, del CMA y RN referidos a los Estudios de Impacto A mbiental (EIA) artkulo 28 del citado cuerpo de leyes.

16 Los daños ambientales merecen ser tratados por el Derecho de manera singular. A demás de reparador, debe ser disuasivo con el objetivo de eliminar o reducir la producción de este tipo de daños de niveles favorables. A gregando finalmente, que estos daños pueden ser previstos por el agente cuasante del daño.

17 Decimos tortuoso al asimilar los principios de la culpa subjetiva y de la teoría objetiva y adolece de un tratamiento sistemático, todos los daños no son iguales.
} 
Y, los daños civiles ambientales no están definidos en nuestra legislación y el problema se agrava al no contar con una infraestructura procesal-judicial cómo tratar estos daños, y las protestas colectivas quedaran restringidos a los vericuetos y páramos estériles del proceso tradicionalista. 